\title{
The Use of Solar Batteries in Agriculture and Accounting of Generated Electricity
}

\author{
Klychova G.S. \\ Iskhakov A.T. ${ }^{1}$ \\ Kazan State Agricultural University, Kazan, 420015, Russia \\ 'Email address: iat20@yandex.ru
}

\section{Doi:10.5901/mjss.2014.v5n12p187}

\section{Abstract}

This article considers the issues of application of solar in agriculture, its performance and perspectives, and also the peculiarities of alternative energy accounting. It describes the composition of the solar battery and a brief description of each component. In this article are given the selection methods of necessary equipment set of solar batteries on the basis of a given need or auxiliary power supply. Offering the method for calculating the efficiency of solar in agriculture with application payback period indicator.

Keywords: solar batteries, alternative energy, efficiency of solar, solar electric power accounting, agriculture.

\section{Introduction}

This work was supported by the grant of the Kazan State Agricultural University No 17/13-HИP from 13.05.2013.

It should be noted that agricultural enterprises belong to the real sector of economy, producing foodstuffs, fodder for agricultural animals, etc. which is inherent the increased power consumption in the production process, which affects the efficiency and profitability of financial and economic activity of agricultural enterprises. In turn, government policy is aimed at developing of this sector of economy, through the implementation of the state program of agriculture development [1].

Electricity, heat and gas supply are some of the major cost items in the manufacturing process of all agricultural enterprises. Taking into account the inflation processes in the country, here is a smooth increase in energy tariffs, and this in turn affects the growth of the production cost and goods prices.

Thus, the use of alternative energy sources in modern economic conditions, including agriculture is urgent and related to the possibility of reducing production costs, increasing farms competitiveness in terms of Russia's accession to the WTO, improvement of ecological production. any form. [9]

Solar Energy is the direction of alternative energy, based on the direct use of solar radiation to generate energy in

\section{Theory}

Currently, there are many recommendations on the use of solar batteries, its relevance in the literature, however this information is difficult for an average representative of the agricultural enterprises of small farms to make a quick decision on application in one or another situation of this energy source in order to improve production efficiency in the enterprise.

Also, the use of alternative energy sources at the agriculture enterprises of Tatarstan republic is minimal, in this regard, there are no calculations and the approbation results of solar in the industry.

In agriculture, solar batteries can be used to supply electricity for livestock farms and equipment, to maintain optimum temperature in premises of farm animals. With their help it is possible to ensure the safety of the territory of agricultural land and to graze cattle using "electroshepherd" - the special fences, which allow to conduct paddock without the presence of people and deters predators. "Electroshepherd" operates on the principle of stun gun, safe for life and health of livestock, and can be recharged by solar batteries.

Solar modules can also be used in plant growing and beekeeping. The collection of plants and honey is often done in rather remote places where is not always access to transmission lines. It can help keep pumping of honey with an electric extractor, cut out honeycomb by electric knife, etc.

In addition, it is possible to connect any industrial, agricultural enterprises subsidiary plants to autonomous power 
supply [2-5].

Thus, the use of solar batteries in agriculture is wide. The main question for most users applying this technology will be "As far as profitable and efficient use of solar batteries in agriculture? How to choose the necessary set of solar batteries for certain purposes? What should be fully autonomous solar batteries? What are the costs needed to produce during the exploitation of solar batteries and how often to carry out the replacement of equipment? How to increase the efficiency of solar batteries in production? Are there special methods of efficiency calculation of this technology application?" and many other questions.

\section{Results}

In this regard, we have developed a method of calculating the efficiency of solar electricity application and selection of necessary equipment. The brief description of the method is given below.

It should be noted that the main components of the solar batteries are: solar panels, voltage inverter, accumulators, controller of battery charge.

First to calculate the efficiency and selection of the equipment it is necessary to determine how much power will be needed to the user per month or other calculation period $[5,8]$.

For this it is necessary to make a list of all electrical appliances, which will be used in the production process or personal use. Each device requires mandatory information about its capacity and peak inrush load. This information can be obtained in the passport of the appliance.

Next is determined the amount of each type of electrical appliances and the average time of their use per day, week, or month for accounting the total energy consumption for the calculated period of time.

Then solar users must choose for themselves depending on the purpose desired mode of using the system of autonomous power supply: full, comfortable, moderate or emergency.

Full power - this mode, meaning the complete replacement of network power supply on autonomous, without any limits of the production process or habitual lifestyle.

Comfortable electricity differs from full mode only except the most "gluttonous" consumers.

Moderate energy supply - in this mode power features significantly influence the operations. First of all this influence is the constant accounting of current load on the autonomous energy supply and the need of turning on all more or less powerful consumers not simultaneously but alternately. In addition, in this mode it is always necessary to remember about the economy, for example, to turn on the light only where it is required and as much as it is really needed. The same applies to all other electrical appliances.

Emergency mode implies a hard limit of needs, however, unlike the previous cases, it is assumed that autonomous operation in this mode will not last more than a few days in a row, therefore many power-consuming appliances may not be used before returning to normal power supply. The task of the emergency power supply is to ensure minimum facilities and functioning of the most important life support systems of production or house.

According to the results of the selected mode, it is necessary to calculate the following parameters: total monthly electricity consumption, average load, a maximum load, maximum inrush load.

After one or another mode of power supply by means of solar batteries is chosen and the total electricity demand is known, it is necessary to select the equipment for solar batteries, providing the power supply[7, 11].

The main element of the solar battery is a solar panel, as the converter of sunlight into electricity. It should be noted that the panels can be made of different materials, have different manufacturing techniques and thus have different parameters of efficiency.

Thus, to calculate the required number of solar panels, it is needed the information about the insolation (solar radiation), the square of one solar panel and efficiency of the panel.

It should be noted that insolation at different times of the year or months of the year varies, for example, in winter in the Central part of Russia yearly solar radiation will be minimal, if the user of solar battery aims to provide year-round autonomous power supply, this option should be taken into account when calculating the required amount of solar modules.

From the point of view of the consumer, solar power systems have a serious drawback: the mode of power generation is not compatible neither with the rhythm of production during the industrial use of solar energy, nor with highenergy (clock) demands of individual customers. Solar power plants can work effectively only part of the day light as in the morning and evening sunlight intensity decreases. But this is time of peak electricity consumption. Therefore, the accumulation and saving energy is a major challenge in the development of photoelectric power systems.

Reliability and efficiency of photovoltaic plants is largely determined by the correct choice of rechargeable batteries 
[9-10].

The selection of batteries for specific solar electrical system is determined by several factors, the main of which are: low self-discharge, the ability to work with small charging currents and deep discharge modes, flexibility at low temperatures (this applies to systems of year-round use), minimal maintenance requirements.

To make photovoltaic system functioning with maximum efficiency, it is important to choose not only the type of battery, but its capacity. Capacity - is the amount of energy that can be stored in the battery. It is measured in amperehours (A/h). For example, one rechargeable battery with capacity of $100 \mathrm{~A} / \mathrm{h}$ can supply the load current of 1 ampere for 100 hours or current of 4 amperes for 25 hours. [1]

The capacity of battery pack is chosen depending on the daily consumption of electricity, considering the depth of the discharge, and working hours, during which the system must operate without recharging.

To increase the service life of the rechargeable battery it is important to prevent a complete discharge, i.e. it is desirable to use only a small part of its capacity before recharging. The charging cycle is every charge-discharge process. If the battery is designed for use over $50 \%$ of the energy stored in it such a battery is called "deep discharge".

The battery performance and its service life are directly dependent on charge-discharge cycles. At very high charging current decreases the amount of electrolyte in the battery, and there is a great possibility of the full failure of the battery. Deep discharge also affects the condition of the battery. Discharges of more than $70 \%$ level reduces the total number of charge-discharge cycles and, consequently period of operation. Frequent battery replacement increases the cost of the entire system.

To prevent overcharge of the battery in photovoltaic stations, as in the other autonomous systems, charge controller is needed. The controller of charge-discharge, therefore, is an important element of a solar power station, influencing the efficiency of the battery and its longevity.

To connect the battery in a single unit preferably through a serial connection. With a parallel connection the total capacity of the battery system will be equal to the total capacity constituting the battery pack, the general voltage will remain unchanged and equal to the voltage of a single battery.

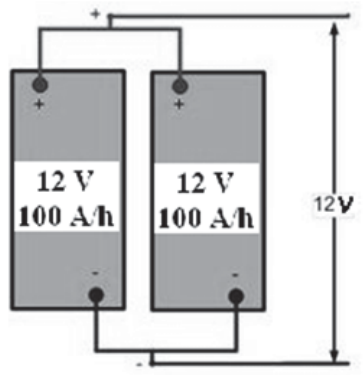

Fig. 1. Parallel connection of batteries (capacity $200 \mathrm{~A} / \mathrm{h}$, voltage $12 \mathrm{~V}$ ) [2]

In series connection the battery pack capacity is equal to the capacity of a single battery, and the battery voltage is equal to the sum of the batteries voltage included in it.

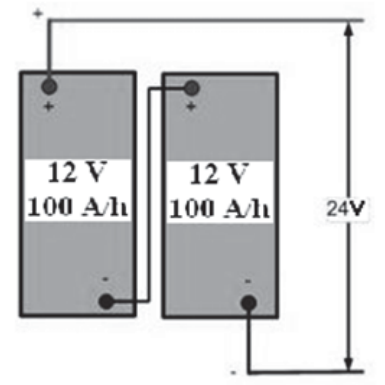

Fig. 2. A serial connection of batteries (general capacity of $100 \mathrm{a} / \mathrm{h}$, voltage $24 \mathrm{~V}$ ) [2] 
Energy stored in such battery pack, equal to the sum of the energies of separately taken batteries (or the product of energy of one battery on their total number, in case the batteries are the same), regardless of the connection method parallel or serial. [1]

Next, it is necessary to calculate the appropriate inverter power. The power of inverter must be with a reserve of 25-50\% more power of maximum electrical appliances load in agricultural production or personal consumption.

After the above calculations are made and parameters of the necessary equipment for a complete set of solar batteries are obtained the user may order the complete set of solar batteries and subsidiary equipment from the supplier with providing the necessary information. Thus, the user will be able to determine the cost of purchasing equipment and its installation.

It should be noted that for calculation of solar batteries using efficiency, including agriculture, the next step is to consider the fact that during the calculated period, this or that equipment in the complete set of solar batteries can be damaged, or to loose its useful properties, or the service life of the equipment is shorter than the period of efficiency calculation of solar batteries. Thus, it is important in the calculations to obtain information about the operation costs for maintenance of the solar battery.

The last step in the calculation is determining the average cost of $1 \mathrm{~kW} / \mathrm{h}$ of electricity derived from solar batteries during the billing period. Also, for comparison it is possible to calculate the unit cost of electrical energy received from the energy companies taking into account inflation for the whole calculated period. 13].

It should be noted that electricity of solar batteries may consider applying for this energy-accounting counters [11,

For example, if install and register the bidirectional counter, for accounting generated and used electricity it is possible receive some cost savings.

Solar energy will "untwist" counter back when energy consumption is minimal or absent, and to compensate for it's "winding" forward when the network electricity is used to the maximum, i.e. there will be uploading of the generated electricity to the internal network and compensate for the lack of power installed transformer $[14,15]$.

In this case, the own generated electricity at the plant in accounting is assigned to the inventories, for example, account 43 "Finished products" with a separate sub-account of the second or third order "Electricity of solar batteries". The cost of this energy will be formed from the actual costs that are associated with its production, for example, in the accounts 20 "Primary production" or 23 "Auxiliary production" with a separate sub-accounts of the second or third order "Electricity generation with solar batteries".

There is the example of correspondence of accounts in organizing accounting of produced solar electricity by direct costs:

- Dr 20 "Basic production", 23 "Auxiliary production" Cr 02 "Amortization of fixed assets", 10 "Materials", 60 "Payments to suppliers and contractors", 70 "Settlements with employees on payment ", 69 "Settlements on social insurance and welfare", 76 "Calculations with different debtors and creditors" and others - there reflect costs directly related to the generation of energy;

- $\quad$ Dr 43 "Finished products" Cr 20 "Basic production", 23 "Auxiliary production" - electric power is reflected as finished products;

- $\quad$ Dr 10 "Materials" $\mathrm{Cr} 43$ "Finished products" -it is debited electricity intended for own needs;

- Dr 20 "Basic production", 23 "Auxiliary production" Cr 10 "Materials" - it is written off to the production the electric power, used for own needs;

- $\quad$ Dr 90 "Sales" Cr 43 "Finished products" - it is written off to the implementation the electricity production cost;

- Dr 62 "Settlements with buyers and customers" Cr 90 "Sales" - reflects the revenue from realization of electricity;

- Dr 90 "Sales" Cr 68 "Settlements on taxes and duties" - VAT is charged.

It should be noted that the reflection of the above described operations in accounting and tax accounting is not complicated. The only thing that cost of a kilowatt hour of electricity for own needs may exceed the rates of professional sales companies. Therefore it is recommended in the accounting policy of the enterprise provide the necessary standards.

\section{Conclusion}

Thus, by the results of this research, we give answers to important questions of using solar electricity in agriculture like: As far as profitable and efficient the use of solar batteries in agriculture? How to choose the necessary set of solar batteries for certain purposes? What should be fully autonomous solar battery? What are the costs needed to produce 
during the exploitation of solar batteries and how often to carry out the replacement of equipment? How to increase the efficiency of solar batteries in production? Are there special methods of efficiency calculation of this technology application? Accounting peculiarities of alternative energy of own production. Further researchers interest in this subject will only grow, which is associated with the search for alternative and ecological sources of energy.

\section{References}

Ismagilova G.N., Safiullin L.N., Bagautdinova N.G. Tourism development in region based on historical heritage. Life Science Journal 2014; 11(6s):363-367.

How to calculate the solar system? // Green Penguin [Electronic resource]. - Mode of access: http://grepen.com.ua/articles/istochnikienergii/kak-rasschitat-solnechnuju-sistemu/

Equipment for solar batteries // Alternative energy [Electronic resource]. - Mode of access: http://batsol.ru/oborudovanie-dlyasolnechnyx-batarej.html

Fakhrutdinova E., Severyanov O., Shigabutdinov A., Fakhrutdinov R. The crisis of 1998 in Russia: political intervention and its implications. Life Science Journal 2014; 11(6s): 442 - 447.

The use of solar batteries in agriculture $/ /$ PowerFilm Solar [Electronic resource]. - Mode of access: http://www.powerfilmsolar.ru/employment/primenenie-solnechnyx-batarej-v-selskom-xozyajstve/

Calculation of electricity consumption // Factory of current - reserve and autonomous power supply [Electronic resource]. - Mode of access: http://www.fabrikatoka.ru/pages/calculator.php

Calculation of solar batteries // Alternative energy [Electronic resource]. - Mode of access: http://batsol.ru/raschet-solnechnyxbatarej.html

Website "Free energy" [Electronic resource]. - Mode of access: http://www.solarroof.ru/

Safiullin L.N., Shigabieva A.M., Mazitov V.M., Saipullaev U.A. Some methodological foundation of an innovation theory. Life Science Journal 2014; 11(6s): 388 - 391.

Solar energy // the Free encyclopedia "Wikipedia" [Electronic resource]. - Mode of access: http://ru.wikipedia.org/wiki/Solnechnaya

Kundakchyan R.M., Zulfakarova L.F. Current issues of optimal capital structure based on forecasting financial performance of the company. Life Science Journal 2014; 11(6s): 368-371.

Solar battery // Free encyclopedia "Wikipedia" [Electronic resource]. - Mode of access: http://ru.wikipedia.org/wiki/Solnechnaia

Safiullin L.N., Fatkhiev A.M., Safiullina L.M. Projected trends and problems of education. Life Science Journal 2014; 11 (6s): 384-387.

Accounting of own electricity for industrial purposes // Largo Management Group Electronic resource]. - Mode of access: http://largo.ru/blog/accounting/post/uchet_sobstvennoy_elektroenergii_dlya_proizvodstvennykh_nuzhd-874/

Ajupov A. Definitions of concepts scope and interaction of risk-engineering on the financial market. Life Science Journal 2014; 11(6s): 337-340. 